Polymer Journal, Vol. 9, No. 1, pp 19-22 (1977)

\title{
Ring-Opening Polymerization of 1-Substituted Azetidine. I. Polymerization of $1-\beta-$ Cyanoethylazetidine with Cationic Initiators
}

\author{
Shizunobu Hashimoto, Takayuki Yamashita, and Junichi Hino \\ Department of Applied Chemistry, Doshisha University, \\ Karasuma-imadegawa, Kamikyo-ku, Kyoto 602, Japan.
}

(Received May 21, 1976)

\begin{abstract}
The ring-opening polymerization of $1-\beta$-cyanoethyl azetidine was investigated in bulk and in solution. The bulk polymerization of 1- $\beta$-cyanoethylazetidine proceeded with cationic initiators such as methyl tosylate and 3-hydroxy-1-propane sulfonic acid sultone at $60^{\circ} \mathrm{C}$, and a white powdery polymer was obtained. In the solution polymerization, the polymerization rate was found to be fast in high polar solvents such as acetonitrile, and an almost quantitative yield was obtained after about $24 \mathrm{hr}$ at $40^{\circ} \mathrm{C}$. The structure of the polymer obtained was confirmed by IR and NMR spectra, and was established as follows:
\end{abstract}

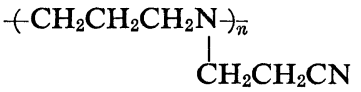

KEY WORDS Ring-Opening Polymerization / 1- $\beta$-Cyanoethylazetidine / Cationic Initiator / Structure of Polymer /

Many works have been reported by different authors on the ring-opening polymerization of three-membered cyclic imines such as ethyleneimine $^{1}$ and $N$-phenylethyleneimine ${ }^{2}$ with a cationic initiator.

In a previous paper, ${ }^{3}$ we described the ringopening polymerization of 1 -substituted aziridine with methyl tosylate, 3-hydroxy-1-propane sulfonic acid sultone (PS), and methyl iodide. The effect of 1-substituted group of aziridine in the ring-opening reaction was very interesting. For example, in the polymerization of lower basic monomer, 1- $\beta$-cyanoethylaziridine, the high molecular weight polymer was produced, while a more basic monomer, 1-phenethylaziridine, could not produce the high molecular weight polymer.

On the other hand, very little is known about the ring-opening polymerizations of the fourmembered cyclic imines, except those of azetidine, ${ }^{4}$ of conidine, ${ }^{5}$ and of 1,3,3-trimethylazetidine. ${ }^{6}$ Therefore, in this paper, the ringopening polymerization of $1-\beta$-cyanoethylazetidine (CEA) as a four-membered cyclic imine was studied and compared with the polymerization of $1-\beta$-cyanoethylaziridine.

\section{RESULTS AND DISCUSSION}

\section{Bulk Polymerization}

The bulk polymerization of CEA was carried out with various cationic initiators at $60^{\circ} \mathrm{C}$. The results are shown in Table I. CEA could be polymerization under the influence of cationic initiators such as methyl tosylate, $\mathrm{PS}, \mathrm{CH}_{3} \mathrm{I}$, and trifluoroacetic acid, and we obtained the white powdery polymer in high yield. Alkyl sulfonic acid esters, such as methyl tosylate and PS were very efficient initiators in CEA polymerization. It had not been expected that CEA could be polymerized with $\mathrm{CH}_{3} \mathrm{I}$ and trifluoroacetic acid, because $1-\beta$-cyanoethylaziridine could not be polymerized with the above initiators.

In the polymerization of $1-\beta$-cyanoethylaziridine, a three membered cyclic imine, the above initiators were unsuitable, and the low molecular weight polymer and the cyclic oligomers, the piperazine derivatives, were obtained because of 
Table I. Ring-opening polymerization of $1-\beta$-cyanoethyl azetidine in bulka

\begin{tabular}{ccccc}
\hline & & \multicolumn{3}{c}{ Polymer } \\
\cline { 3 - 5 } Initiator $^{\mathrm{b}}$ & $\begin{array}{c}\text { Reaction } \\
\text { time, hr }\end{array}$ & $\begin{array}{c}\text { Yield, } \\
\%\end{array}$ & $\mathrm{mp},{ }^{\circ} \mathrm{C}$ & $\eta_{\mathrm{sp}} / C^{\mathrm{c}}$ \\
\hline PS & 24 & 93.2 & $54-57$ & 0.19 \\
MT & 0.5 & 70.0 & $59-62$ & 0.17 \\
$\prime \prime$ & 1 & 78.0 & $57-60$ & 0.18 \\
$\prime \prime$ & 3 & 91.4 & $57-58$ & 0.20 \\
$\prime \prime$ & 24 & 93.4 & $54-57$ & 0.19 \\
MI & 24 & 89.4 & $54-57$ & 0.11 \\
TFA & 24 & 80.6 & $54-56$ & 0.09 \\
\hline
\end{tabular}

a Monomer, $5.0 \mathrm{mmol}$; initiator, $2 \mathrm{~mol} \%$ of monomer; reaction temperature, $60^{\circ} \mathrm{C}$.

b PS, 3-Hydroxy-1-propane sulfonic acid sultone; MT, methyl tosylate; MI, methyl iodide; TFA, trifluoroacetic acid.

c $C=0.5 \mathrm{~g} / 100 \mathrm{~m} l$ in $D M F$ at $30^{\circ} \mathrm{C}$.

the termination reaction (eq 1$).^{7}$<smiles>CCNCCCN1CC1</smiles><smiles>CC[N+]1(CCC#N)CCN(CCC#N)CC1</smiles>

\section{Solution Polymerization}

The solution polymerization of CEA initiated with methyl tosylate at $40^{\circ} \mathrm{C}$ was carried out in the following solvents: high polar solvents with high dielectric constant such as acetonitrile (dielectric constant $\varepsilon=37.5$ ), polar solvents such as tetrahydrofuran $(\varepsilon=7.39)$, and non-polar solvents such as benzene $(\varepsilon=2.27)$. The results of the polymerization of CEA in the various solvents are shown in Table II.

As shown in Table II, the yield of polymer in the solution polymerization was lower than that in the bulk polymerization. The reaction time of $48 \mathrm{hr}$ was further required to obtain the high yield of polymer in the polymerization with methyl tosylate in acetonitrile.

The polymerization rate of CEA was found to be fast in acetonitrile, but slow in tetrahydrofuran and in benzene. In spite of the polarity of tetrahydrofuran, the polymerization rate of
Table II. Ring-opening polymerization of 1 - $\beta$-cyanoethyl azetidine with MT in various solvents ${ }^{\mathrm{a}}$

\begin{tabular}{|c|c|c|c|c|}
\hline \multirow{2}{*}{$\begin{array}{l}\text { Solvent, } \\
\quad 2 \mathrm{ml}\end{array}$} & \multirow{2}{*}{$\begin{array}{l}\text { Reaction } \\
\text { time, hr }\end{array}$} & \multicolumn{3}{|c|}{ Polymer } \\
\hline & & $\underset{\%}{\text { Yield, }}$ & $\mathrm{mp},{ }^{\circ} \mathrm{C}$ & $\eta_{\mathrm{sp}} / C^{\mathrm{b}}$ \\
\hline Acetonitrile & 5 & 24.8 & $53.0-55.0$ & 0.08 \\
\hline " & 12 & 56.8 & $62.5-64.9$ & 0.16 \\
\hline " & 24 & 65.6 & $60.0-63.0$ & 0.17 \\
\hline " & 48 & 81.8 & $63.8-65.0$ & 0.18 \\
\hline " & 120 & 86.8 & $62.9-64.0$ & 0.19 \\
\hline THF & 5 & 15.6 & $50.5-51.5$ & 0.05 \\
\hline " & 12 & 37.3 & $57.0-60.8$ & 0.11 \\
\hline " & 24 & 44.4 & $56.0-60.0$ & 0.12 \\
\hline " & 48 & 63.9 & $57.5--58.5$ & 0.13 \\
\hline " & 120 & 67.7 & $57.8-59.4$ & 0.13 \\
\hline Benzene & 5 & 17.9 & $49.5-51.0$ & 0.06 \\
\hline$" \prime$ & 12 & 31.0 & $56.7-58.0$ & 0.10 \\
\hline " & 24 & 41.5 & $55.0-56.0$ & 0.11 \\
\hline " & 48 & 56.0 & $55.0-56.0$ & 0.18 \\
\hline$" \prime$ & 120 & 65.3 & $55.0-58.0$ & 0.18 \\
\hline
\end{tabular}

a Monomer, $5 \mathrm{mmol}$; MT, $2 \mathrm{~mol} \%$ of monomer; reaction temperature, $40^{\circ} \mathrm{C}$.

b $C=0.5 \mathrm{~g} / 100 \mathrm{ml}$ in $\mathrm{DMF}$ at $30^{\circ} \mathrm{C}$.

CEA in tetrahydrofuran was the same as that in benzene which was a nonpolar solvent. The slow rate in tetrahydrofuran was probably due to the solvation by coordination of the oxygen in the tetrahydrofuran-ring to the immonium cation, the propagating species of the polymer end.

In the polymerization of CEA with PS in acetonitrile, an almost quantitative conversion was attained after about $24 \mathrm{hr}$; the conversion was $99.4 \%$ in the solution polymerization of CEA with PS (CEA, $5.0 \mathrm{mmol}$ in acetonitrile $2 \mathrm{ml}$; PS, $5 \mathrm{~mol} \%$ of monomer; $40^{\circ} \mathrm{C}$ ).

The polymerization of CEA with PS was assumed to be initiated by eq 2 , and then a cationic polymerization was presumed, as shown in eq 3 .

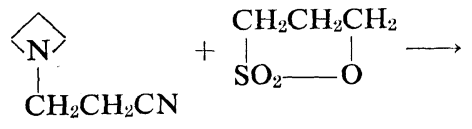

(I)<smiles>COS(=O)(=O)CCCC[N+]1(CCC#N)CCC1</smiles> 


$$
\begin{aligned}
& \text { (II) }+n(\mathbf{I}) \longrightarrow
\end{aligned}
$$

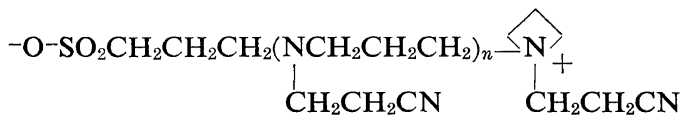

\section{Polymer Characterization}

The IR spectrum of the polymer obtained had a $\nu_{\mathrm{C} \equiv N}$ absorption at $2260 \mathrm{~cm}^{-1}$, as shown in Figure 1. The NMR spectrum consisted of two kinds of broad absorptions at $2.6 \mathrm{ppm}$ and one at $1.6 \mathrm{ppm}$ : the absorptions at $2.6 \mathrm{ppm}$ were assigned respectively to the three methylene group adjacent to nitrogen and the methylene group adjacent to the cyano group, and the absorption

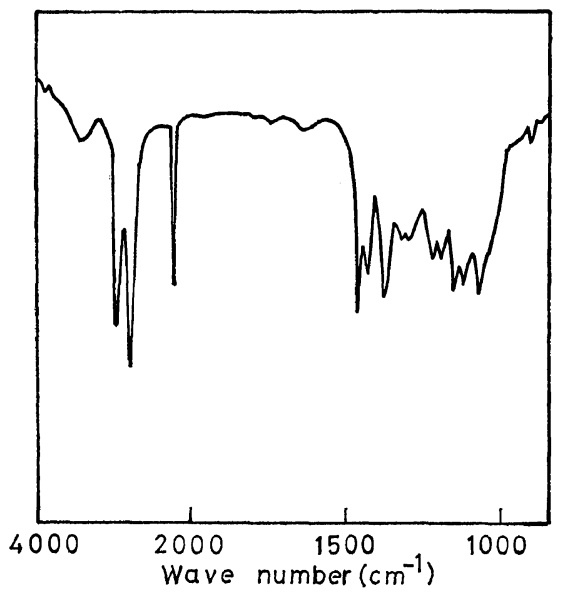

Figure 1. Infrared spectrum of poly(1- $\beta$-cyanoethylazetidine) $(\mathrm{KBr})$.

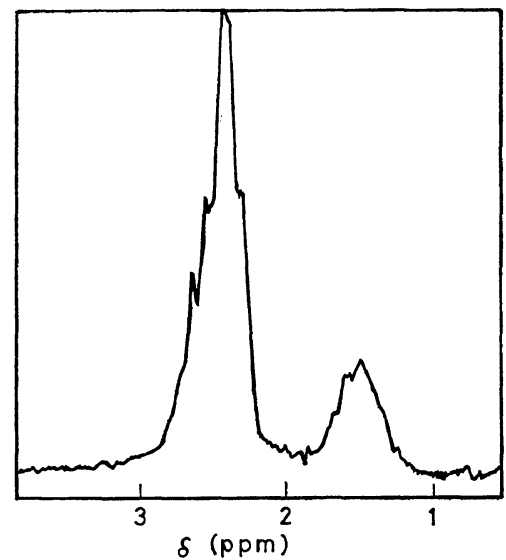

Figure 2. NMR spectrum of poly(1- $\beta$-cyanoethylazetidine) ( $60 \mathrm{Mc}$, in $\left.\mathrm{CDCl}_{3}\right)$.

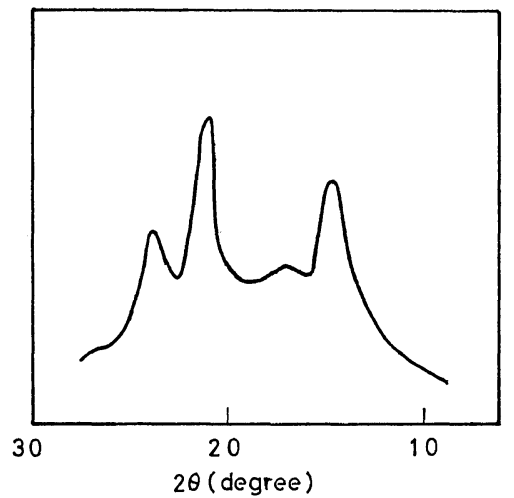

Figure 3. X-ray diffraction curve of poly(1- $\beta$ cyanoethyl azetidine).

of $1.6 \mathrm{ppm}$ was assigned to the remaining methylene group in the polymer chain (Figure 2).

The CEA polymer is a crystalline solid. The $\mathrm{X}$-ray diffraction curve is shown in Figure 3. The X-ray diffraction curve showed three crystalline peaks at $2 \theta=14.6^{\circ}, 21.0^{\circ}$, and $24.9^{\circ}$.

The result of the elemental analysis of this polymer showed the composition of CEA monomer.

Anal. Calcd for $\left(\mathrm{C}_{6} \mathrm{H}_{10} \mathrm{~N}_{2}\right)_{n}$ : C, 65.42; H, 9.15; N, 25.43. Found: C, 64.8; H, 9.9; N, 25.2

This polymer is soluble in dimethyl sulfoxide, acetone and conc. hydrochloric acid, and insoluble in water, methanol, ether, and cyclohexane. From these results, the structure of this polymer was confirmed as follows.

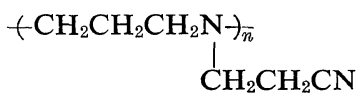

\section{EXPERIMENTAL}

\section{Reagents}

Acetonitrile, tetrahydrofuran, and benzene as a solvent were commercial reagents which were dried over $\mathrm{P}_{2} \mathrm{O}_{5}$ or metallic sodium and then purified by distillation. PS, methyl tosylate, $\mathrm{CH}_{3} \mathrm{I}$, and trifluoroacetic acid as a initiator were commercial reagents which were distilled under dry nitrogen atomosphere before use.

Preparation of 1- $\beta$-Cyanoethylazetidine

Azetidine. This compound was prepared in ca. $60-\%$ yield as described by Wadsworth. ${ }^{8}$ The 


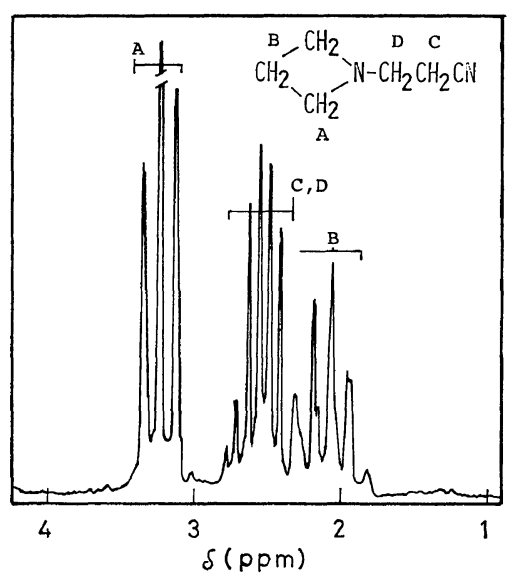

Figure 4. NMR spectrum of 1- $\beta$-cyanoethylazetidine (ca. $5 \%$ in $\mathrm{CD}_{3} \mathrm{CN}, 60 \mathrm{Mc}$ ).

product was collected as the fraction boiling at $75-85^{\circ} \mathrm{C}$.

1- $\beta$-Cyanoethyl Azetidine. This compound was prepared as described by Teng-yueh, et $a .^{9}{ }^{9}$ Acryronitrile $6.2 \mathrm{~g}(0.12 \mathrm{~mol})$ was added at $5^{\circ} \mathrm{C}$, to a stirred solution of azetidine $5.9 \mathrm{~g}(0.104 \mathrm{~mol})$ in $10 \mathrm{~m} l$ of ether. The resulting solution was then evaporated off, and the residue was distilled under nitrogen atomosphere, bp $85-90^{\circ} \mathrm{C} / 20$ $\mathrm{mmHg}$ (lit., ${ }^{9} 85-91^{\circ} \mathrm{C} / 20 \mathrm{mmHg}$ ) (yield, ca. $60 \%$ ). The NMR spectrum of CEA is shown in Figure 4 and the IR spectrum has a $\nu_{\mathrm{C} \equiv \mathrm{N}}$ absorption at $2260 \mathrm{~cm}^{-1}$. The molecular weight determined by GC-Mass was 110 .

Polymerization of 1- $\beta$-Cyanoethylazetidine

The polymerization was carried out in a sealed tube. CEA was placed into a glass tube. Then an initiator was added to this solution with a microsyringe and the mixture was shaken vigorously. The reaction mixture was thermostated at $60^{\circ} \mathrm{C}$ for the required time. After the polymerization, the reaction mixture was poured into excess ether, and the precipitated polymer was filtrated, and then washed with ether and dried in vacuo to constant weight.

The solution polymerization was carried out in the same manner as described above, after the addition of solvent.

\section{REFERENCES}

1. For example, W. G. Barb, J. Chem. Soc., 1955, 2564.

2. T. Kagiya and Y. Sumida, Bull. Chem. Soc. Jpn., 41, 767 (1968).

3. S. Hashimoto, T. Yamashita, and M. Ono, Kobunshi Ronbunshu, 33, 83 (1976).

4. E. H. Shacht and E. J. Goethals, Makromol. Chem., 175, 3447 (1974).

5. E. F. Rasvodovskii, et al., J. Macromol. Sci., A8, 241 (1974).

6. E. H. Shacht and E. J. Goethals, Makromol. Chem., 167, 155 (1973).

7. S. Hashimoto and T. Yamashita, presented at the 29th Annual Meeting of the Chemical Society of Japan, April 1976; to be submitted for publication.

8. H. Wadsworth, J. Org. Chem., 32, 1184 (1967).

9. Teng-yueh Chen, H. Kato, and M. Ohta, Bull. Chem. Soc. Jpn., 40, 1964 (1967). 